\title{
Black-White Achievement Gap: Role of Race, School Urbanity, and Parental Education
}

This article was published in the following Dove Press journal:

Pediatric Health, Medicine and Therapeutics

\author{
Shervin Assari (D) \\ Abbas Mardani $\mathbb{D}^{2}$ \\ Maryam Maleki ${ }^{3}$ \\ Shanika Boyce ${ }^{4}$ \\ Mohsen Bazargan ${ }^{1,5}$ \\ 'Departments of Family Medicine, \\ Charles R Drew University of Medicine \\ and Science, Los Angeles, CA 90059, \\ USA; ${ }^{2}$ Nursing Care Research Center, \\ School of Nursing and Midwifery, Iran \\ University of Medical Sciences, Tehran, \\ Iran; ${ }^{3}$ School of Nursing and Midwifery, \\ Shahroud University of Medical Sciences, \\ Shahroud, Iran; ${ }^{4}$ Departments of \\ Pediatrics, Charles R Drew University of \\ Medicine and Science, Los Angeles, CA \\ 90059, USA; ${ }^{5}$ Departments of Family \\ Medicine, University of California, Los \\ Angeles (UCLA), Los Angeles, CA \\ 90095, USA
}

Background: Recent research on Marginalization-related Diminished Returns (MDRs) has documented weaker boosting effects of parental educational attainment on educational outcomes of Black than White students. Such MDRs of parental education seem to contribute to the Black-White achievement gap. Given that Blacks are more likely than Whites to attend urban schools, there is a need to study if these MDRs can be replicated at both urban and suburban schools.

Aim: To test the contribution of diminished returns of parental educational attainment on the Black-White achievement gap in urban and suburban American high schools.

Methods: A cross-sectional study that used baseline Education Longitudinal Study (ELS2002) data, a nationally representative study of 10th grade adolescents in the United States. This study analyzed 8315 youths who were either non-Hispanic White $(n=6539,78.6 \%)$ or non-Hispanic Black $(\mathrm{n}=1776,21.4 \%)$ who were attending either suburban $(\mathrm{n}=5188$, $62.4 \%)$ or urban $(n=3127,37.6 \%)$ schools. The outcome was standard math and reading grades. The independent variable was parental educational attainment. Gender, parental marital status, and school characteristics (\% free lunch and relationship quality with the teacher) were the confounders. Race/ethnicity was the effect of modifier. School urbanity was the strata. Linear regression was used for data analysis.

Results: In urban and suburban schools, higher parental educational attainment was associated with higher math and reading test scores. In urban and suburban schools, Black students had considerably lower reading and math scores than White students. At urban but not suburban schools, significant interactions were found between race (Non-Hispanic Black) and parental education attainment (years of schooling) on reading and math scores, suggested that the protective effect of parental education on students' reading and math scores (ie school achievement) is smaller for Non-Hispanic Black relative to Non-Hispanic White youth only in urban but not sub-urban schools.

Conclusion: Diminished returns of parental education (MDRs) contribute to the racial achievement gap in urban but not suburban American high schools. This result is important given Black students are more likely to attend urban schools than White students. As MDRs are not universal and depend on context, future research should study contextual characteristics of urban schools that contribute to MDRs.

Keywords: population groups, socioeconomic status, youth, adolescents, education, academic gap, school achievement

\section{Introduction}

Educational success plays an important role in shaping people's future opportunities in life. ${ }^{1}$ Students who perform better at school are more likely to gain higher salaries, ${ }^{2}$ become active citizens, ${ }^{3}$ experience higher life satisfaction, ${ }^{4}$ and avoid
Department of Family Medicine, Charles R Drew University of Medicine and Science, Los Angeles, CA, USA Email assari@umich.edu
Pediatric Health, Medicine and Therapeutics 202I:I2 I-I I

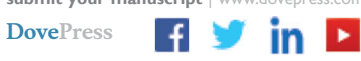


high risk and criminal behaviors ${ }^{5}$ during adulthood. Given that students' academic achievement (eg test scores) is a substantial predictor of economic and non-economic outcomes later in life, ${ }^{5}$ it is necessary to address racial inequalities in school performance, also known as the Black-White achievement gap.

Previous research has shown persistent and large racial inequalities of academic achievement in the United States school system, which is in part due to the low quality of education at urban schools. ${ }^{6}$ Urban schools provide a lower quality of education because of fewer resources, leading to lower academic achievement among students. ${ }^{7}$ The Black-White achievement gap, however, remains significant beyond controlling for school urbanity as a covariate. ${ }^{8}$ It is, however, unknown whether Black-White achievement gap can be seen within both urban and suburban schools.

Child's academic achievement is affected by school socioeconomic status (SES). ${ }^{9}$ Concentration of poverty among students who attend urban schools is considered one of the greatest contributors to low academic achievement in such contexts. ${ }^{10}$ Recent studies demonstrate that poverty has both a direct impact on student achievements through cognitive ability ${ }^{11}$ and education quality. ${ }^{12}$ For example, differential teacher quality may explain some of the achievement gap between Blacks and Whites. ${ }^{13}$ Children of low SES families start school less prepared ${ }^{14}$ and academically perform worse than their peers with higher family SES at school. ${ }^{10}$ This is another reason we need to differentially study contributors of the BlackWhite gap in predominantly Black (suburban) and White (suburban) schools.

Family SES is also among the major determinants of students' school achievement. ${ }^{9}$ Among SES indicators, parental education is among the most stable aspects of family SES background, ${ }^{15}$ which influence the quality of home learning settings ${ }^{16}$ and higher levels of parental engagement in children's schooling. ${ }^{16,17}$ Children of loweducated parents more so than students with highly educated parents tend to demonstrate lower educational achievement. ${ }^{18}$ Parents with higher education levels can provide greater SES resources which influences the academic achievement of their children, ${ }^{19}$ but lower SES in Black parents can be restricted their investment in their children. $^{20}$

Eligibility for using free or reduced price lunch (FRPL) is one of the other indicators of SES that may predict student academic achievement. ${ }^{21}$ FRPL is a proxy of school SES. ${ }^{21,22}$ Predominantly Black and urban schools have higher FRPL usage than predominantly White and suburban schools. ${ }^{23}$ Students who are FRPL eligible score lower in reading and math test scores than equivalent students who were not eligible for FRPL. ${ }^{24}$

The educational attainment gap between students of low SES and high SES is observable at the age of seven, and at the end of compulsory education. ${ }^{10}$ In addition, education aspiration, especially among poor students, has been connected to academic achievement, ${ }^{25}$ such that over time and when approaching the end of compulsory education, educational aspirations fall in low-income students. ${ }^{14}$

In the US, students with low family SES are most likely to attend urban schools. ${ }^{26}$ On the other hand, children who go to urban schools in low-income neighborhoods show lower academic progress. ${ }^{27,28}$ Indeed, sixthgrader children in the wealthiest school regions compared to children in the poorest regions are four grade levels ahead. ${ }^{29}$ In addition, the high percentage of students with low family SES in urban schools is related to lowers the engagement and attempt of all students. ${ }^{7}$

In the US education system, schooling and residential place are closely connected. As a result, residential neighborhoods affect both the value of property (wealth) and the racial and socioeconomic composition of schools. ${ }^{30}$ Therefore, the role of race could be disadvantageous for the academic achievement of minorities. ${ }^{23}$ In spite of the modest decreases in the Black-White residential segregation, Black students remain concentrated in racially segregated public schools in urban zones where a higher percentage of the population is from the racial or ethnic minority groups with low income. ${ }^{31} \mathrm{~A}$ previous study showed schools in the poor regions have insufficient resources and elementary education quality varies drastically racial lines. ${ }^{32}$ Also, research has shown lower academic achievement obtain in urban schools and schools where a greater part of the student body is Blacks. $^{31,33}$

Race is closely linked to family SES. ${ }^{34}$ Race is also associated with school SES and racial composition. ${ }^{35}$ Schools with a high concentration of minorities have lower SES. ${ }^{36}$ School social status, student-teacher ratio, class size, teacher selection, and school rules are influenced by school SES. ${ }^{23}$ African American students in mainly Black schools both in advanced and general classes are more likely to be exposed to a less demanding curriculum due to lower teacher quality and expectations ${ }^{31}$ which lead to the academic achievement gap. 
Furthermore, a significant factor in enhancing student educational achievement is teacher quality. ${ }^{37}$ Educational background, professional certifications, and teaching experience of teachers improve student achievement in schools. ${ }^{38}$ Studies in the US have shown that students' academic achievement may be three times higher when taught by a high-quality teacher. ${ }^{39}$ But evidence indicates that schools with a high percentage of minority students are more likely to have lower qualified and experienced teachers with higher rates of teachers' turnover. ${ }^{40,41}$ Also, new teachers inclined to start their work in schools with greater concentrations of low SES students do so to acquire more experience and then tend to transfer to higher-SES schools. ${ }^{30}$ In addition, poor and Black students are more probably taught by teachers who have an alternative certification. ${ }^{6}$

Although Black and White students' academic achievement gap improved across time, ${ }^{42}$ this gap still exists and substantial especially in urban schools. ${ }^{6,43}$ Recent data revealed the achievement gap between White and Black youth in reading and math remained relatively constant over the past years. ${ }^{44}$ Additionally, the Black-White academic achievement gap in both reading and math scores during the first 4 years of the primary school nearly 0.10 standard deviations increased each year. ${ }^{45}$ Research suggests this gap may be due to the SES achievement gap between minorities and the majority group. ${ }^{46}$ However, in recent years, the relationship between race and SES also is dropping. ${ }^{47}$

Research has revealed that racial/ethnicity minorities may not receive equal gains from their SES compared to dominant racial/ethnic groups, ${ }^{48,49}$ identified as Marginalization-related Diminished Returns (MDRs). ${ }^{50,51}$ In the US, marginalization-related diminished returns of SES indicators (eg education attainment, income) are established across domains of health ${ }^{52}$ such as exercise, ${ }^{53}$ diet, ${ }^{54}$ smoking, ${ }^{55,56}$ depression, ${ }^{57,58}$ anxiety, ${ }^{59}$ mental well-being, ${ }^{60}$ self-rated mental health, ${ }^{61}$ and chronic medical conditions. ${ }^{54}$ Recent research has also documented diminished returns of parental educational attainment on school performance of Black children. ${ }^{62}$

Recently, diminished returns of parental educational attainment have been investigated on student academic performances of minorities group in the US population. In two studies, parental educational attainment has smaller positive effects on grade point average (GPA) in Hispanic and Black than non-Hispanic White youth ${ }^{62}$ and nonHispanic Blacks than non-Hispanic Whites college students. ${ }^{63}$ The result of another study indicated that the family socioeconomic position at birth has a smaller protective result for school bonding in Black than White youth. ${ }^{64}$

To investigate diminished returns of parental education on the school performance of elementary students, we applied a nationally representative sample to compare Black and White students reading and math scores as a function of race and parental education. We tested these effects across urban and suburban schools. Our hypothesis is that Black and White students' academic performance are differently affected by parental education and available resources in urban and suburban schools. If we could observe diminished returns of parental education in both urban and suburban schools, then diminished returns of parental education is not just a problem of urban schools. MDR are also not all because Black and White students attend different schools. If diminished returns exist in urban schools but not in suburban schools, urban school would be the context that generates MDR. We hypothesized that urban schools (low education quality and poor education context) not suburban schools will show MDR. That means we expect urban schools to be a mechanism by which parental education generates less outcomes for Black than White students.

\section{Methods \\ Design and Settings}

This cross-sectional study is a secondary analysis of Wave 1 of the Education Longitudinal Study (ELS) study ${ }^{65}$ Funded by the US Department of Education (DOE), ELS is one of the main studies of youth education in the US. The ELS sample is representative of $10^{\text {th }}$ grade youth in the US. Although ELS has enrolled all race/ethnic groups, this analysis was limited to 10,702 youth who were composed of 2020 (18.9\%) non-Hispanic Black and 8682 (81.1\%) non-Hispanic White youth. Exclusion criterion in the current analysis was any race other than White or Black.

\section{Ethics}

All participating youth provided written assent. Youth parents signed written consent. The institutional review board (IRB) of the Department of Education (DOE) approved the protocol of the original article. As this analysis used fully deidentified public data, this secondary analysis was deemed to be exempted from a full IRB review. 


\section{Sample and Sampling}

The ELS youth sample was enrolled in the private, public, or Catholic schools. These schools could be selected from either Urban, Suburban, or Rural areas. ELS used a multistage stratified random sample. The analytical sample of this study was 10,702 .

\section{Study Variables}

The study variables included race/ethnicity as the moderating variable, parental education as the independent variable (predictor), youth math and reading test scores as the outcomes (dependent variables), and demographic factors (gender and parental marital status) and school characteristics (\% students receiving free lunch).

\section{Race/ethnicity}

Race/ethnicity, a dichotomous variable, was self-identified as non-Hispanic Black (1) versus on-Hispanic White (0).

\section{Parental Educational Attainment (Independent Variable)}

Parental educational attainment was a continuous variable that reflected the highest number of years of schooling in parents. This variable was self-reported by the parents.

\section{Demographic Factor (Covariates)}

Gender and family structure were demographic covariates. Parental marital status was a dichotomous variable $(1=$ married parents, $0=$ unmarried parents) and calculated based on parents' marital status. Gender was $1=$ male $0=$ female.

\section{School characteristics}

School characteristics included school control system (public versus private), and \% students receiving free lunch. Both these variables were administrative rather than self-report.

\section{School Urbanity}

School urbanity was a dichotomous variable: $1=$ urban schools, $0=$ suburban schools. This variable was administrative, not self-report.

\section{School Function/Achievement (Outcomes)}

Our dependent variables were standardized test scores of math and reading. These variables were transformed to $z$ scores which helps comparison of the students and interpretation of the regression coefficients. Students performed the test.

\section{Statistical Analysis}

SPSS 23.0 (IBM Corporation, Armonk, New York, US) was used to analyze the data. We had normally distributed outcomes thus we decided to perform linear regressions. There was no multicollinearity between our independent variables such as race/ethnicity and parental educational attainment. Our model passed the assumption of homoscedasticity (eg, distribution of error terms). This strategy also helped us with the comparability of MDR across our two outcomes. We ran two hierarchical linear regression models per outcome, in the pooled sample. The first block of variables only included race/ethnicity. Our second block included educational attainment (years of schooling). Block 3 included the educational attainment (years) by race/ethnicity interaction term. The fourth block included gender and parental marital status. The fifth block included school characteristics, namely, relation with the teacher and \% students with free lunch. We reported beta (b), B, standard error (SE), and $p$ value.

\section{Results \\ Descriptive Data}

Table 1 provides descriptive statistics for our sample. This study included 8315 youth. From this number, most were non-Hispanic White $(\mathrm{n}=6539,78.6 \%)$ and a minority were non-Hispanic Black $(\mathrm{n}=1776,21.4 \%)$. From all participants, most were attending either suburban schools $(\mathrm{n}=5188,62.4 \%)$ and a minority were attending urban schools $(\mathrm{n}=3127,37.6 \%)$.

\section{Bivariate Analysis}

Table 2 presents the summary of bivariate analysis in the pooled sample. Reading and math test scores were closely correlated $(\mathrm{r}=0.75, \mathrm{p}<0.001) . \%$ free lunch at school was inversely correlated with reading $(r=-0.33, p<0.001)$ and math $(\mathrm{r}=-0.36, \mathrm{p}<0.001)$ scores. Urban school was correlated with lower math $(\mathrm{r}=-0.03, \mathrm{p}<0.001)$ but not reading ( $\mathrm{p}>0.05)$ score. Race (Black) was negatively correlated with both reading $(\mathrm{r}=-0.34, \mathrm{p}<0.001)$ and math $(r=-0.39, p<0.001)$ scores.

\section{Multivariable Models}

Table 3 presents the summary of two hierarchical linear regression models in suburban schools. In both these models, race (non-Hispanic Black) and parental educational attainment were associated with the outcomes (reading and math scores). These models did not show statistical interactions between parental educational attainment and race on youth 
Table I Descriptive Characteristics

\begin{tabular}{|c|c|c|c|c|c|c|}
\hline \multirow[t]{2}{*}{ Qualitative Variables } & All $n=8315$ & & Suburban $n=5188$ & & Urban $n=3127$ & \\
\hline & $\mathbf{n}$ & $\%$ & $\mathbf{n}$ & $\%$ & $\mathbf{n}$ & $\%$ \\
\hline \multicolumn{7}{|l|}{ School Urbanity } \\
\hline Suburban & 5188 & 62.4 & 5188 & 100.0 & 0 & 0 \\
\hline Urban & 3127 & 37.6 & 0 & 0 & 3127 & 100.0 \\
\hline \multicolumn{7}{|l|}{ Race (Black) * } \\
\hline Non-Hispanic White & 6539 & 78.6 & 4386 & 84.5 & 2153 & 68.9 \\
\hline Non-Hispanic Black & 1776 & 21.4 & 802 & 15.5 & 974 & 31.1 \\
\hline \multicolumn{7}{|l|}{ Gender } \\
\hline Female & 4204 & 50.6 & 2631 & 50.7 & 1573 & 50.3 \\
\hline Male & 4111 & 49.4 & 2557 & 49.3 & 1554 & 49.7 \\
\hline \multicolumn{7}{|l|}{ Parental Marital Status* } \\
\hline Not- Married & 3325 & 40.0 & 1992 & 38.4 & 1333 & 42.6 \\
\hline Married & 4990 & 60.0 & 3196 & 61.6 & 1794 & 57.4 \\
\hline Quantitative variables & Mean & SD & Mean & SD & Mean & SD \\
\hline Parental education (years) $*$ & 4.81 & 2.00 & 4.66 & 1.99 & 5.05 & 2.01 \\
\hline Teacher student relation* & 0.34 & 0.74 & 0.30 & 0.72 & 0.42 & 0.78 \\
\hline$\%$ Free Lunch & 2.86 & 1.89 & 2.89 & $\mathrm{I} .77$ & 2.83 & 2.07 \\
\hline Test Score (Reading) & 51.82 & 9.83 & 51.76 & 9.62 & 51.91 & 10.16 \\
\hline Test Score (Math) * & 51.57 & 9.73 & 51.79 & 9.45 & $5 \mathrm{I} .2 \mathrm{I}$ & 10.17 \\
\hline
\end{tabular}

Note: $* p<0.05$.

Table 2 Correlations in the Pooled Sample $(n=8315)$

\begin{tabular}{|c|c|c|c|c|c|c|c|c|c|}
\hline & I & 2 & 3 & 4 & 5 & 6 & 7 & 8 & 9 \\
\hline I School Urbanity (Urban) & I & $0.19 * *$ & $0.09 * *$ & 0.00 & $-0.04^{* *}$ & $0.08 * *$ & -0.02 & 0.01 & $-0.03 * *$ \\
\hline 2 Race (Black) & & I & $-0.13^{* *}$ & -0.00 & $-0.30^{* *}$ & $-0.06 * *$ & $0.39 * *$ & $-0.34 * *$ & $-0.39 * *$ \\
\hline 3 Parental education (years) & & & I & 0.01 & $0.15 * *$ & $0.09 * *$ & $-0.31 * *$ & $0.33 * *$ & $0.34 * *$ \\
\hline 4 Gender (Male) & & & & I & 0.02 & -0.00 & 0.00 & $-0.07^{* *}$ & $0.07 * *$ \\
\hline 5 Parental Marital Status (Married) & & & & & I & $0.09 * *$ & $-0.25 * *$ & $0.23 * *$ & $0.25 * *$ \\
\hline 6 Teacher student relation & & & & & & I & $-0.12^{* *}$ & $0.13^{* *}$ & $0.14 * *$ \\
\hline 7\% Free Lunch & & & & & & & I & $-0.33^{* *}$ & $-0.36 * *$ \\
\hline 8 Test Score (Reading) & & & & & & & & I & $0.75^{* *}$ \\
\hline 9 Test Score (Math) & & & & & & & & & 1 \\
\hline
\end{tabular}

Note: $* * p<0.01$.

educational outcomes. No interaction terms suggest that the link between high parental educational attainment and youth educational outcomes (grades) is similar for non-Hispanic Black than and Non-Hispanic White youth.

Table 4 presents the summary of two hierarchical linear regression models in urban schools. In both these models, race (non-Hispanic Black) and parental educational attainment were associated with the outcomes. These models showed an interaction between parental education and youth outcomes. These interaction terms suggest that the positive link between parental education and youth educational outcomes (grades) is smaller for non-Hispanic Black relative to Non-Hispanic White youth. These findings suggest that in urban schools, non-Hispanic Black youth with highly educated parents have low school performance, and these diminished returns of parental education. 
Table 3 Associations Between Race and Parental Education on Reading and Math Score at Suburban Schools

\begin{tabular}{|c|c|c|c|c|c|}
\hline & B (Std. Error) & B (Std. Error) & B (Std. Error) & B (Std. Error) & B (Std. Error) \\
\hline \multicolumn{6}{|l|}{ Reading } \\
\hline Race (Black) & $-7.90(0.42)^{* * *}$ & $47.32(0.38) * * *$ & $-6.41(0.96)^{* * *}$ & $-5.77(0.96)^{* * *}$ & $-5.10(0.96)^{* * *}$ \\
\hline Parental Education & - & $-7.16(0.40) * * *$ & $1.35(0.08)^{* * *}$ & $1.30(0.08)^{* * *}$ & $1.16(0.08)^{* * *}$ \\
\hline Black* Education (Years) & - & - & $-0.17(0.20)$ & $-0.17(0.20)$ & $-0.18(0.20)$ \\
\hline Gender (Male) & - & - & - & $-1.99(0.28)^{* * *}$ & $-2.01(0.28)^{* * *}$ \\
\hline Parental Marital Status & - & - & - & $2.06(0.30)^{* * *}$ & $\mathrm{I} .77(0.30)^{* * * *}$ \\
\hline Teacher student relation & - & - & - & - & $0.95(0.20)^{* * *}$ \\
\hline$\%$ free lunch & - & - & - & - & $-0.50(0.09)^{* * *}$ \\
\hline \multicolumn{6}{|l|}{ Math } \\
\hline Race (Black) & $-9.04(0.40)^{* * *}$ & $-8.25(0.38)^{* * *}$ & $-7.04(0.92)^{* * *}$ & $-6.42(0.91)^{* * *}$ & $-5.67(0.91)^{* * *}$ \\
\hline Parental Education & - & $\mathrm{I} .4 \mathrm{I}(0.07)^{* * *}$ & $\mathrm{I} .46(0.07)^{* * *}$ & $1.38(0.07)^{* * *}$ & $1.24(0.08)^{* * *}$ \\
\hline Black* Education (Years) & - & - & $-0.28(0.19)$ & $-0.27(0.19)$ & $-0.28(0.19)$ \\
\hline Gender (Male) & - & - & - & $1.13(0.27)^{* * *}$ & $\mathrm{I} . \mathrm{II}(0.27)^{* * *}$ \\
\hline Parental Marital Status & - & - & - & $2.16(0.29)^{* * *}$ & $1.85(0.29)^{* * *}$ \\
\hline Teacher student relation & - & - & - & - & $0.97(0.19)^{* * *}$ \\
\hline$\%$ free lunch & - & - & - & - & $-0.56(0.08)^{* * *}$ \\
\hline
\end{tabular}

Note: $* * * p<0.001$.

Table 4 Associations Between Race and Parental Education on Reading and Math Score at Urban Schools

\begin{tabular}{|c|c|c|c|c|c|}
\hline & B (Std. Error) & B (Std. Error) & B (Std. Error) & B (Std. Error) & B Std. Error \\
\hline \multicolumn{6}{|l|}{ Reading } \\
\hline Race (Black) & $-9.45(0.42)^{* * *}$ & $-8.06(0.4 I)^{* * *}$ & $-4.94(1.03)^{* * *}$ & $-4.06(1.04)^{* * *}$ & $-5.10(0.96)^{* * *}$ \\
\hline Parental Education & - & $1.36(0.09)^{* * *}$ & $1.54(0.1 \mathrm{I})^{* * *}$ & $1.48(0.1 \mathrm{I})^{* * *}$ & $1.16(0.08)^{* * *}$ \\
\hline Black* Education (Years) & - & - & $-0.68(0.21)^{* *}$ & $-0.66(0.20)^{* *}$ & $-0.18(0.20)$ \\
\hline Gender (Male) & - & - & - & $-0.86(0.36)^{*}$ & $-2.0 \mathrm{I}(0.28)^{* * *}$ \\
\hline Parental Marital Status & - & - & - & $2.46(0.39)^{* * *}$ & $\mathrm{I} .77(0.30)^{* * *}$ \\
\hline Teacher student relation & - & - & - & - & $0.95(0.20)^{* * *}$ \\
\hline$\%$ free lunch & - & - & - & - & $-0.50(0.09)^{* * *}$ \\
\hline \multicolumn{6}{|l|}{ Math } \\
\hline Race (Black) & $54.99(0.21)^{* * *}$ & $47.87(0.52)^{* * *}$ & $46.56(0.59)^{* * *}$ & $44.33(0.65)^{* * * *}$ & $47.13(0.73)^{* * *}$ \\
\hline Parental Education & - & $-9.00(0.40)^{* * *}$ & $-4.91(1.00)^{* * *}$ & $-3.85(0.99)^{* * *}$ & $-2.5 \mathrm{I}(0.99)^{*}$ \\
\hline Black* Education (Years) & - & - & $1.57(0.10)^{* * *}$ & $\mid .5 \mathrm{I}(0.10)^{* * *}$ & $1.29(0.10)^{* * *}$ \\
\hline Gender (Male) & - & - & - & $-0.90(0.20)^{* * * *}$ & $-0.87(0.19)^{* * *}$ \\
\hline Parental Marital Status & - & - & - & $1.39(0.34)^{* * *}$ & $1.46(0.33)^{* * *}$ \\
\hline Teacher student relation & - & - & - & - & $1.95(0.37)^{* * *}$ \\
\hline$\%$ free lunch & - & - & - & - & $1.06(0.22)^{* * *}$ \\
\hline
\end{tabular}

Notes: ${ }^{*} \mathrm{p}<0.05$; ${ }^{* *} \mathrm{p}<0.01$; *** $\mathrm{p}<0.001$.

\section{Discussion}

The current study showed four findings: First, high parental education was linked to higher math and reading scores among youth. Second, in urban but not suburban schools, the boosting effect of parental education on school achievement is weaker for non-Hispanic Black than for Non-Hispanic White families.
Third, parental education differently influenced reading and math scores at urban schools above and beyond relation with children, marital status of the parents, and \% free lunch eligibility of the students. Fourth, at suburban schools, Black and White students similarly gain school performance from their parental education. 
Diminished returns of education contribute to the Black-White academic gap in urban schools only. At urban schools, Black students remain at educational risk, despite their highly educated parents. Such level of risk is unexpected and disproportionate to their parental educational attainment.

As MDR remained as a contributor to the Black-White achievement gap in urban but not suburban school characteristics, we argue that urban school context may be a probable cause for diminished returns of parental educational attainment as a cause of racial achievement gap. Still, as shown by previous studies, other upstream social forces that occur beyond education system may also contribute to such gap. For example, labor market discrimination may put Black parents in worse jobs, which may reduce Black parents' available time to engage with their children's school activities. However, differential context of education of Black and White youth seems to be essential for Black-White achievement gaps due to MDR. ${ }^{66}$

With a similar pattern observed in urban schools, Black students with highly educated parents have shown to report poor school outcomes,${ }^{67}$ poor school attainment, ${ }^{51}$ and poor school bonding, ${ }^{68}$ all outcomes that are disproportionate to their high parental education. Previous research, however, could not tell whether these patterns can be observed in both urban and suburban settings.

One recent study documented worse than expected aggression, chronic diseases, tobacco use, psychological problems, and school performance in Black youth with high parental education. ${ }^{66}$ As argued in other studies, ${ }^{69-71}$ a plausible conclusion seems to be that some distal and upstream social processes interfere with the effects of parental education for racial and ethnic minority families. ${ }^{66}$ According to this study, however, diminished returns of parental education are not all because Black youth attending urban schools where the quality of schooling is lower.

The education system seems not to be the only reason we see worse outcomes for Black youth in the middle class with highly educated parents. Diminished returns of parental and own education result in higher than expected prevalence of asthma, ${ }^{72}$ Attention Deficit Hyperactivity Disorder, ${ }^{73}$ mental health problems, ${ }^{74}$ depression, ${ }^{75,76}$ obesity, ${ }^{61,77}$ dental health problems, ${ }^{78}$ poor health-care use, ${ }^{79}$ impulsivity control, ${ }^{80}$ and cigarette smoking ${ }^{81}$ in middle class Black families. Similar patterns are shown for Black adults, ${ }^{82-84}$ Black youth, ${ }^{77,80,85}$ Hispanic adults, ${ }^{56,86,87}$ and Hispanic youth. ${ }^{66}$ As similar patterns are shown for various groups, it is not a group behavior but the upstream underlying mechanisms such as social stratification, structural racism, and marginalization that reduce the positive effects of education for minority families. ${ }^{66}$

While parental education promotes educational outcomes for youth, this association is diminished for Non-Hispanic Black and White youth. The smaller marginal returns of parental education are beyond what can be explained by school characteristics that differ between Non-Hispanic Black and non-Hispanic White students. Diminishing returns of parental educational attainment (MDR) may be an unrecognized source of racial youth disparities. Equalizing SES would not be enough for equalizing outcomes. There is a need for public and economic policies that reduce diminished returns of SES for Black families.

The major contribution of this study is that we found diminished returns of parental education in urban but not suburban schools. That is, diminished returns of parental education may be specific to the context, thus modifiable through educational policies. This results in advocates for policies that target the education quality of urban schools. We argue that Black youth from the middle class perform worse than expected in part because they are more likely to attend urban schools. They would probably do similar to White middle-class youth if they had the chance to attend suburban schools.

Racial inequalities and disparities are not all due to the lower SES of Blacks as inequalities can be also seen in middle-class people. Thus, other social mechanisms are at work to cause inequalities across racial groups, even for middle-class families that access education.

\section{Policy Implications}

These results have considerable implications. Innovative policies, as well as public health programs, should be designed, implemented, and evaluated to reduce racial and ethnic inequalities across all levels of SES strata. To address disparities that are not due to low SES but diminished return of SES, we should go beyond exclusively focusing on equalizing access to resources. While equal access is important, there is a need to address broader social and economic processes that hinder middle-class Black families' abilities to leverage their available resources. Policies should aim to equalize the gain that follows access to SES resources. Such policies are hoped to reduce inequalities that sustain across all the SES spectrum. $^{55,59,77-80,82,86,88,89}$ We need policies and program solutions that equalize highly educated Black families' abilities to leverage their educational 
attainment. $^{88,90}$ Some suspect the cause of MDR are labor market practices and preferences. ${ }^{82}$ Although there are strong anti-discrimination laws, further enforcement of such existing policies may be required if we want to minimize the existing diminishing marginal returns of education and other SES indicators in the lives of Black families. Communities, where the majority of residents are Black, may benefit from higher quality and abundant jobs that facilitate translation of educational attainment into tangible real-life outcomes. ${ }^{91}$ Programs should help highly educated Black parents successfully compete with Whites to secure high paying jobs. At the same time, we should reduce the societal and environmental barriers that are common in the everyday lives of Black population. In addition, we should invest in educational programs and in outcomes of Black youth, including middle-class Black youth, in urban and suburban schools. There is a need to empower Black parents to utilize their education and increase their engagement with their children's school performance. Finally, we need to minimize the discrimination of Black students in urban and suburban schools. ${ }^{92,93}$

\section{Limitations}

This study had a few limitations. With our cross-sectional design, we cannot make any causal inferences. The unequal sample size across groups prevented us from running race-specific models. This study only included NonHispanic Blacks and Non-Hispanic Whites. Other ethnic minorities such as Hispanics, Asians, and Native Americans should be included in future studies. We only studied the differential effect of parental educational attainment. Other family SES indicators such as wealth, income, employment, and area-level SES should be studied. This study did not include geocoded data. Thus, educational policies were not included. Despite these limitations, this study still contributes to the MDR literature on as well as the racial achievement gap. Some strengths included a large sample size, a random sample, and a representative sample that resulted in generalizable findings to the US, and standardized tests. However, the main contribution of this study is beyond these methodological strengths. This was the first study showing that diminished returns of parental education on school performance can be seen in both urban and suburban schools, thus these diminished returns are not all because of poor urban schools that are weak in educational quality.

\section{Conclusion}

In the United States, non-Hispanic Black youth who attend urban schools are at a disadvantage compared to NonHispanic White youth regarding the magnitude of the effect of parental education on their educational outcomes. Such diminished returns of parental education that are observable in urban schools are absent in suburban schools. Context of education may be one reason Black youth from middleclass families do worse than middle-class White youth.

\section{Disclosure}

The authors report no conflicts of interest in this work.

\section{References}

1. Ilie S, Lietz P. School quality and student achievement in 21 European countries. Iss Methodol Large Scale Assessments. 2010;57-84.

2. Caro DH, Cortina KS, Eccles JS. Socioeconomic background, education, and labor force outcomes: evidence from a regional US sample. $\mathrm{Br} J$ Sociol Educ. 2015;36(6):934-957. doi:10.1080/01425692.2013.868784

3. Marshall J. The Anti-Democrat Diploma: how High School Education Decreases Support for the Democratic Party. Am J Pol Sci.. 2019;63(1):67-83. doi:10.1111/ajps.12409

4. Tabbodi M, Rahgozar H, Makki Abadi MM. The relationship between happiness and academic achievements. Eur Online $J$ Nat Soc Sci. 2015;4:241-246.

5. Browning MH, Rigolon A. School green space and its impact on academic performance: A systematic literature review. Int J Environ Res Public Health. 2019;16(3):429. doi:10.3390/ijerph16030429

6. Talbert-Johnson C. Structural inequities and the achievement gap in urban schools. Educ Urban Soc. 2004;37(1):22-36. doi:10.1177/ 0013124504268454

7. Sandy J, Duncan K. Examining the achievement test score gap between urban and suburban students. Educ Economics. 2010;18 (3):297-315. doi:10.1080/09645290903465713

8. Assari SBM, Caldwell CH, Zimmerman MA. Diminished Returns of Parental Educational Attainment on School Achievement of NonHispanic Black High School Students. Under Review. 2020;1:1254.

9. Abrams K, Kong F. The Variables Most Closely Associated with Academic Achievement: A Review of the Research Literature. Omaha, NE:: Progressive Research Institute of Nebraska; 2012:1-27.

10. West A. Poverty and educational achievement: why do children from low-income families tend to do less well at school? Benefits. 2007;15:283-297.

11. Nelson CA, Sheridan MA. Lessons from neuroscience research for understanding causal links between family and neighborhood characteristics and educational outcomes. Whither Opportunity. 2011;2746.

12. Schmidt WH, Burroughs NA, Zoido P, Houang RT. The role of schooling in perpetuating educational inequality: an international perspective. Educ Res. 2015;44(7):371-386. doi:10.3102/ 0013189X15603982

13. Goldhaber D, Lavery L, Theobald R. Uneven playing field? Assessing the teacher quality gap between advantaged and disadvantaged students. Educ Res. 2015;44(5):293-307. doi:10.3102/ 0013189X15592622

14. Rutkowski D, Rutkowski L, Wild J, Burroughs N. Poverty and educational achievement in the US: A less-biased estimate using PISA 2012 data. $J$ Children Poverty. 2018;24(1):47-67. doi:10.1080/10796126.2017.1401898 
15. Augustine JM. Increased educational attainment among US mothers and their children's academic expectations. Res Soc Stratif Mobil. 2017;52:15-25. doi:10.1016/j.rssm.2017.08.001

16. Augustine JM. Maternal education and the unequal significance of family structure for children's early achievement. Social Forces. 2014;93(2):687-718. doi:10.1093/sf/sou072

17. Shapiro M. Parental education level: academic involvement and success. 2009.

18. Bakar NA, Mamat I, Ibrahim M. Influence of Parental Education on Academic Performance of Secondary School Students in Kuala Terengganu. Int J Acad Res Business Social Sci. 2017;7(8):296304. doi:10.6007/IJARBSS/v7-i8/3230

19. Hosokawa R, Katsura T. A longitudinal study of socioeconomic status, family processes, and child adjustment from preschool until early elementary school: the role of social competence. Child Adolesc Psychiatry Ment Health. 2017;11:62.

20. Altonji JG, Doraszelski U, Segal L. Black/white differences in wealth. Economic Perspect Federal Res Bank Chicago. 2000;24:38-49.

21. Harwell M, LeBeau B. Student eligibility for a free lunch as an SES measure in education research. Educ Res. 2010;39(2):120-131. doi:10.3102/0013189X10362578

22. Sirin SR. Socioeconomic status and academic achievement: A metaanalytic review of research. Rev Educ Res. 2005;75(3):417-453. doi: $10.3102 / 00346543075003417$

23. Rowley RL, Wright DW. No" white" child left behind: the academic achievement gap between black and white students. J Negro Educ. 2011;80:93.

24. Borg JR, Borg MO, Stranahan HA. Closing the achievement gap between high-poverty schools and low-poverty schools. Res Business Economics J. 2012;5:1.

25. Koo A. Is there any chance to get ahead? Education aspirations and expectations of migrant families in China. Br J Sociol Educ. 2012;33 (4):547-564. doi:10.1080/01425692.2012.678755

26. Crosnoe R. Low-income students and the socioeconomic composition of public high schools. Am Sociol Rev. 2009;74(5):709-730. doi:10.1177/000312240907400502

27. White GW, Stepney CT, Hatchimonji DR, et al. The increasing impact of socioeconomics and race on standardized academic test scores across elementary, middle, and high school. Am J Orthopsychiatry. 2016;86(1):10. doi:10.1037/ort0000122

28. Brown KM, Anfara VA, Roney K. Student achievement in high performing, suburban middle schools and low performing, urban middle schools: plausible explanations for the differences. Educ Urban Soc. 2004;36(4):428-456. doi:10.1177/0013124504263339

29. Kuo M, Browning MH, Sachdeva S, Westphal L, Lee K. Might school performance grow on trees? Examining the link between "greenness" and academic achievement in urban, high-poverty schools. Front Psychol. 2018;9:1669. doi:10.3389/fpsyg.2018.01669

30. Goldring E, Swain W. The School Attendance and Residential Location Balancing Act: Community, Choice, Diversity, and Achievement. Education, Land, and Locations. Ingram GK, Kenyon DA, edited by. Cambridge, MA: Lincoln Institute of Land Policy; 2014:92-116.

31. Lleras C. Race, racial concentration, and the dynamics of educational inequality across urban and suburban schools. Am Educ Res J. 2008;45(4):886-912. doi:10.3102/0002831208316323

32. Condliffe BF, Boyd ML, DeLuca S. Stuck in school: how social context shapes school choice for inner-city students. Teach Coll Rec. 2015;117:1-36.

33. Roscigno VJ. Race and the reproduction of educational disadvantage. Social Forces. 1998;76(3):1033-1061. doi:10.2307/3005702

34. Williams DR, Priest N, Anderson NB. Understanding associations among race, socioeconomic status, and health: patterns and prospects. Health Psychol. 2016;35(4):407. doi:10.1037/hea0000242
35. Xuan X, Xue Y, Zhang C, et al. Relationship among school socioeconomic status, teacher-student relationship, and middle school students' academic achievement in China: using the multilevel mediation model. PLoS One. 2019;14(3):e0213783. doi:10.1371/ journal.pone.0213783

36. Kenty-Drane JL. Early Isolation: Racial and Economic Segregation in US Public Elementary Schools. Race, Gender \& Class; 2009:4562.

37. Hanushek EA, Rivkin SG. Generalizations about using value-added measures of teacher quality. Am Economic Rev. 2010;100(2):267271. doi:10.1257/aer.100.2.267

38. Chu JH, Loyalka P, Chu J, Qu Q, Shi Y, Li G. The impact of teacher credentials on student achievement in China. China Economic Rev. 2015;36:14-24. doi:10.1016/j.chieco.2015.08.006

39. Hanushek EA. The economic value of higher teacher quality. Econ Educ Rev. 2011;30(3):466-479. doi:10.1016/j. econedurev.2010.12.006

40. Rivkin SG, Hanushek EA, Kain JF. Teachers, schools, and academic achievement. Econometrica. 2005;73(2):417-458. doi:10.1111/ j.1468-0262.2005.00584.x

41. Barton PE Parsing the Achievement Gap: baselines for Tracking Progress. Policy Information Report. 2003.

42. Bohrnstedt G, Kitmitto S, Ogut B, Sherman D, Chan D. School Composition and the Black-White Achievement Gap. NCES 2015018. National Center for Education Statistics; 2015.

43. Lacour M, Tissington LD. The effects of poverty on academic achievement. Educ Res Rev. 2011;6:522-527.

44. Olszewski-Kubilius P, Steenbergen-Hu S, Thomson D, Rosen R. Minority achievement gaps in STEM: findings of a longitudinal study of Project Excite. Gifted Child Quarterly. 2017;61(1):20-39. doi:10.1177/0016986216673449

45. Murnane RJ, Willett JB, Bub KL, McCartney K, Hanushek E, Maynard R. Understanding trends in the black-white achievement gaps during the first years of school [with comments]. BrookingsWharton Papers on Urban Affairs. 2006;2006(1):97-135. doi:10.1353/urb.2006.0024

46. Hanushek EA, Peterson PE, Talpey LM, Woessmann L. The Unwavering SES Achievement Gap: Trends in US Student Performance; 0898-2937. National Bureau of Economic Research; 2019.

47. Wilson WJ. The Truly Disadvantaged: The Inner City, the Underclass, and Public Policy. University of Chicago Press; 2012.

48. Assari S, Lankarani MM. Education and alcohol consumption among older Americans; black-white differences. Fron Public Health. 2016;4:67. doi:10.3389/fpubh.2016.00067

49. Montez JK, Hummer RA, Hayward MD. Educational attainment and adult mortality in the United States: A systematic analysis of functional form. Demography. 2012;49(1):315-336. doi:10.1007/s13524011-0082-8

50. Muhammad M, De Loney EH, Brooks CL, Assari S, Robinson D, Caldwell CH. "I think that's all a lie ... I think It's genocide": applying a Critical Race Praxis to Youth Perceptions of Flint Water Contamination. Ethn Dis. 2018;28(Supp 1):241-246. doi:10.18865/ ed.28.S1.241

51. Assari S. Parental Education Attainment and Educational Upward Mobility; Role of Race and Gender. Behav Sci (Basel). 2018;8. doi:10.3390/bs8110107

52. Preiser B, Assari S. Psychological Predictors of Sexual Intimate Partner Violence against Black and Hispanic Women. Behav Sci (Basel). 2017;8. doi:10.3390/bs8010003

53. Assari S. Educational Attainment and Exercise Frequency in American Women; Blacks' Diminished Returns. Women's health bulletin; 2019:6.

54. Assari S, Lankarani M. Educational Attainment Promotes Fruit and Vegetable Intake for Whites but Not Blacks. J. 2018;1:5. 
55. Assari S, Mistry R. Educational Attainment and Smoking Status in a National Sample of American Adults; Evidence for the Blacks' Diminished Return.. Int J Environ Res Public Health. 2018;15 (4):763. doi:10.3390/ijerph15040763

56. Shervin A, Ritesh M. Diminished Return of Employment on Ever Smoking Among Hispanic Whites in Los Angeles. Health Equity. 2019;3(1):138-144. doi:10.1089/heq.2018.0070

57. Williams AJ, Lai Z, Knight S, Kamali M, Assari S, McInnis MG. Risk Factors Associated With Antidepressant Exposure and History of Antidepressant-Induced Mania in Bipolar Disorder. J Clin Psychiatry. 2018;79(3). doi:10.4088/JCP.17m11765

58. Assari S. Race, Intergenerational Social Mobility and Stressful Life Events. Behav Sci (Basel). 2018;8. doi:10.3390/bs8100086

59. Assari S, Caldwell CH, Zimmerman MA. Family Structure and Subsequent Anxiety Symptoms; Minorities' Diminished Return. Brain Sci. 2018;8(6):97. doi:10.3390/brainsci8060097

60. Assari S. Suicide Attempts in Michigan HealthCare System; Racial Differences. Brain Sci. 2018;8(7):124. doi:10.3390/brainsci8070124

61. Assari S. Family Income Reduces Risk of Obesity for White but Not Black Children. Children. 2018;5. doi:10.3390/children5060073

62. Assari S, Caldwell CH. Parental Educational Attainment Differentially Boosts School Performance of American Adolescents; Minorities' Diminished Returns. J Family Rep Health. 2019;7-13.

63. Assari S. Parental Educational Attainment and Academic Performance of American College Students; Blacks' Diminished Returns. J Health Economics Dev. 2019;1:21.

64. Assari S. Family Socioeconomic Position at Birth and School Bonding at Age 15: blacks' Diminished Returns. Behav Sci (Basel). 2019;9(3):26. doi:10.3390/bs9030026

65. Statistics, U.S.D.o.E.N.C.f.E. Education Longitudinal Study (ELS), 2002:: 2005 .

66. Assari S, Caldwell CH. Parental Educational Attainment and Youth Outcomes: hispanics' Diminished Returns. JAMA Network Open. 2020.

67. Assari S. Parental Educational Attainment and Academic Performance of American College Students; Blacks' Diminished Returns. J Health Economics Dev. 2019;1(1):21-31.

68. Assari S. Family Socioeconomic Position at Birth and School Bonding at Age 15; Blacks' Diminished Returns. Behav Sci (Basel). 2019;9. doi:10.3390/bs9030026

69. Mirowsky J, Ross CE. Education, Health, and the Default American Lifestyle. J Health Soc Behav. 2015;56(3):297-306. doi:10.1177/ 0022146515594814

70. Ross CE, Mirowsky J. Refining the association between education and health: the effects of quantity, credential, and selectivity. Demography. 1999;36(4):445-460. doi:10.2307/2648083

71. Ross CE, Mirowsky J. The interaction of personal and parental education on health. Soc Sci Med. 2011;72(4):591-599. doi:10.1016/j.socscimed.2010.11.028

72. Assari S, Moghani Lankarani M. Poverty Status and Childhood Asthma in White and Black Families: national Survey of Children's Health. Healthcare. 2018;6. doi:10.3390/healthcare6020062

73. Assari S, Caldwell CH. Family Income at Birth and Risk of Attention Deficit Hyperactivity Disorder at Age 15: racial Differences. Children. 2019;6. doi:10.3390/children6010010

74. Assari S. Parental Educational Attainment and Mental Well-Being of College Students; Diminished Returns of Blacks. Brain Sci. 2018;8 (11): 193. doi:10.3390/brainsci8110193

75. Assari S, Caldwell CH. High Risk of Depression in High-Income African American Boys. J Racial Ethn Health Disparities. 2018;5 (4):808-819. doi:10.1007/s40615-017-0426-1

76. Assari S, Lankarani MM, Caldwell CH. Does Discrimination Explain High Risk of Depression among High-Income African American Men? Behav Sci (Basel). 2018;8. doi:10.3390/bs8040040
77. Assari S, Thomas A, Caldwell CH, Mincy RB. Blacks' Diminished Health Return of Family Structure and Socioeconomic Status; 15 Years of Follow-up of a National Urban Sample of Youth. $J$ Urban Health. 2018;95(1):21-35. doi:10.1007/s11524-017-0217-3

78. Assari S. Socioeconomic Status and Self-Rated Oral Health; Diminished Return among Hispanic Whites. Dent J. 2018;6. doi:10.3390/dj6020011

79. Assari S, Hani N. Household Income and Children's Unmet Dental Care Need; Blacks' Diminished Return. Dent J. 2018;6. doi:10.3390/ dj6020017

80. Assari S, Caldwell CH, Mincy R. Family Socioeconomic Status at Birth and Youth Impulsivity at Age 15; Blacks' Diminished Return. Children. 2018;5. doi:10.3390/children5050058

81. Bachman JG, O'Malley PM, Johnston LD, Schulenberg JE, Wallace JM. Racial/ethnic differences in the relationship between parental education and substance use among U.S. 8th-, 10th-, and 12thgrade students: findings from the Monitoring the Future project. $J$ Stud Alcohol Drugs. 2011;72(2):279-285. doi:10.15288/ jsad.2011.72.279

82. Assari S. Blacks' Diminished Return of Education Attainment on Subjective Health; Mediating Effect of Income. Brain Sci. 2018;8 (9):176. doi:10.3390/brainsci8090176

83. Assari S. High Income Protects Whites but Not African Americans against Risk of Depression. Healthcare. 2018;6. doi:10.3390/ healthcare 6020037

84. Assari S. The Benefits of Higher Income in Protecting against Chronic Medical Conditions Are Smaller for African Americans than Whites. Healthcare. 2018;6. doi:10.3390/healthcare6010002

85. Assari S, Caldwell CH, Mincy RB. Maternal Educational Attainment at Birth Promotes Future Self-Rated Health of White but Not Black Youth: A 15-Year Cohort of a National Sample. J Clin Med. 2018;7 (5):93. doi:10.3390/jcm7050093

86. Assari S, Farokhnia M, Mistry R. Education Attainment and Alcohol Binge Drinking: diminished Returns of Hispanics in Los Angeles. Behav Sci (Basel). 2019;9. doi:10.3390/bs9010009

87. Assari S. Socioeconomic Determinants of Systolic Blood Pressure; Minorities' Diminished Returns. J Health Economics Dev. 2019;1:111.

88. Assari S. Unequal Gain of Equal Resources across Racial Groups. Int $J$ Health Policy Manag. 2017;7(1):1-9. doi:10.15171/ijhpm.2017.90

89. Assari S, Mistry R, Mistry R, Assari S, Mistry R. Educational Attainment and Smoking Status in a National Sample of American Adults; Evidence for the Blacks' Diminished Return. Int J Environ Res Public Health. 2018;15(4):763. doi:10.3390/ijerph15102084

90. Assari S. Health Disparities due to Diminished Return among Black Americans: public Policy Solutions. Soc Issues Policy Rev. 2018;12 (1):112-145. doi:10.1111/sipr.12042

91. Hazelzet E, Picco E, Houkes I, Bosma H, de Rijk A. Effectiveness of Interventions to Promote Sustainable Employability: A Systematic Review. Int J Environ Res Public Health. 2019;16(11):1985. doi:10.3390/ijerph16111985

92. Assari S, Caldwell CH. Teacher Discrimination Reduces School Performance of African American Youth: role of Gender. Brain Sci. 2018;8(10):183. doi:10.3390/brainsci8100183

93. Chavous TM, Rivas-Drake D, Smalls C, Griffin T, Cogburn C. Gender matters, too: the influences of school racial discrimination and racial identity on academic engagement outcomes among African American adolescents. Dev Psychol. 2008;44:637. doi:10.1037/00121649.44.3.637 


\section{Publish your work in this journal}

Pediatric Health, Medicine and Therapeutics is an international, peerreviewed, open access journal publishing original research, reports, editorials, reviews and commentaries. All aspects of health maintenance, preventative measures and disease treatment interventions are addressed within the journal. Practitioners from all disciplines are invited to submit their work as well as healthcare researchers and patient support groups. The manuscript management system is completely online and includes a very quick and fair peer-review system. Visit http://www.dovepress.com/testimonials.php to read real quotes from published authors. 